\title{
集成产品开发 IPD 在课程设计中的应用研究
}

\section{Research on the Application of IPD in Curriculum Design}

\author{
田宏伟 ${ }^{1}$ 任勇 $^{1}$ 刘雪兰 $^{2}$ \\ Hongwei Tian ${ }^{1}$ Yong Ren $^{1}$ XueLan Liu ${ }^{2}$ \\ 1 苏州大学应用技术学院 中国·江苏昆山 215325；2 江苏农牧科技职业学院 中国 ·江苏泰州 225300 \\ 1 Applied Technology College of Soochow University, Kunshan, Jiangsu, 215325, China; \\ 2 Jiangsu Agri-animal Husbandry Vocational College, Taizhou, Jiangsu, 225300, China
}

摘 要: 随着新经济的快速发展, 行业边界越来越模糊, 学生跨界知识学习能力、解决复杂工程问题的能力、项目管理能力 和经济决策能力都需要全面培养。IPD 模块式是企业解决跨界复杂工程问题的先进方法, 在 RFID 与传感器技术课程实践教学 过程使用，通过校企双方的案例选择和教学内容设计，以及结构化流程的项目开发教学组织，在实践中取得了较好的成果。

\begin{abstract}
Students' cross-border knowledge learning ability, ability to solve complex engineering problems, project management ability and economic decision-making ability need to be comprehensively cultivated. IPD modular is an advanced method for enterprises to solve crossborder complex engineering problems. It is used in the practical teaching process of RFID and sensor technology course. Through the case selection and teaching content design of both schools and enterprises, as well as the project development teaching organization of structured process, good results have been achieved in practice.
\end{abstract}

关键词：集成产品开发；新工科；应用型课程；校企协同

Key words : integrated product development; new engineering; Applied Curriculum; school enterprise collaboration

基金项目：教育部 2019 年第二批产学合作协同育人项目（201902167044）；江苏省现代教育技术研究立项课题（2019-R82197 ）；苏州大学应用技术学院教改项目（JG201807）

DOI: $10.36012 /$ sde.v2i12.2600

\section{1 前言}

新经济的快速发展, 行业边界越来越模糊, 以多学科 交叉的物联网行业企业为例, 企业迫切需要新型的跨界工程 科技人才 ${ }^{[1]}$, 在国家提出的新工科理念下, 工程教育的培养 思路更注重与企业对工程科技人员知识结构和技术创新能 力的需求相对接。

IPD 集成产品开发 (Integrated Product Development) 是 一套产品开发的模式、理念与方法, 最先将 IPD 付诸实践 的是 IBM 公司, 并取得了显著的效果。在 IBM 成功经验的 影响下, 华为公司引入了该生产理念, 并用其所取得的成就 证明了该思想的先进性 ${ }^{[2]}$ 。

IPD 集成产品开发需要计算机领域软件和硬件知识、产
品应用领域知识、经济知识和管理知识等, 要求团队成员 具备学习跨专业跨界知识学习的能力、沟通能力、项目管 理能力和经济决策能力。王润云等提出了一种基于 IPD 结 构化流程的跨专业团队的本科毕业设计模型 ${ }^{[3]}$, 在实际应 用中取得了不错的效果。但是毕业设计一般安排在第七学 期或第八学期, 升学、就业等一些因素会影响具体实施效果, 因此为了实现新兴工科人才能力地培养, 需要将 IPD 集成 产品开发的实施点前移至三年级的教学课程中。

\section{2 集成产品开发的实施}

\section{1 课程选择}

RFID 与传感器技术课程为物联网工程专业第 5 学期的 学位课课程, 该课程的实践教学内容以综合性设计实验为

【作者简介】田宏伟 (1981 ) 男, 山东莒县人, 研究生学历, 高级工程师。从事物联网工程应用教学工作研究。 
主, 教学大纲根据人才培养方案的要求, 除注重 RFID 知识 的综合应用以及综合设计能力培养外, 增加实际企业新产品 开发的全周期实践、协同开发项目管理能力和经济决策能力 培养。

\section{2 教学内容设计}

教学内容来自一线企业实践案例, 并经过了校企双 方教师的共同构建，体现了知识、技术和方法的综合应
用, 案例难度从简单到复杂, 从小单元到大系统, 循序 渐进。

教学以 “基于微信小程序和 ONENet 物联网平台的智 慧家电” 为案例, 该案例包含了嵌入式硬件、嵌入式软件、 物联网平台接口、网络通信协议、微信小程序开发等的实践, 属于基础的复杂工程项目，通过树状形式的复杂问题拆分方 法，可以将该项目拆分为更小的项目，如图 1 所示。

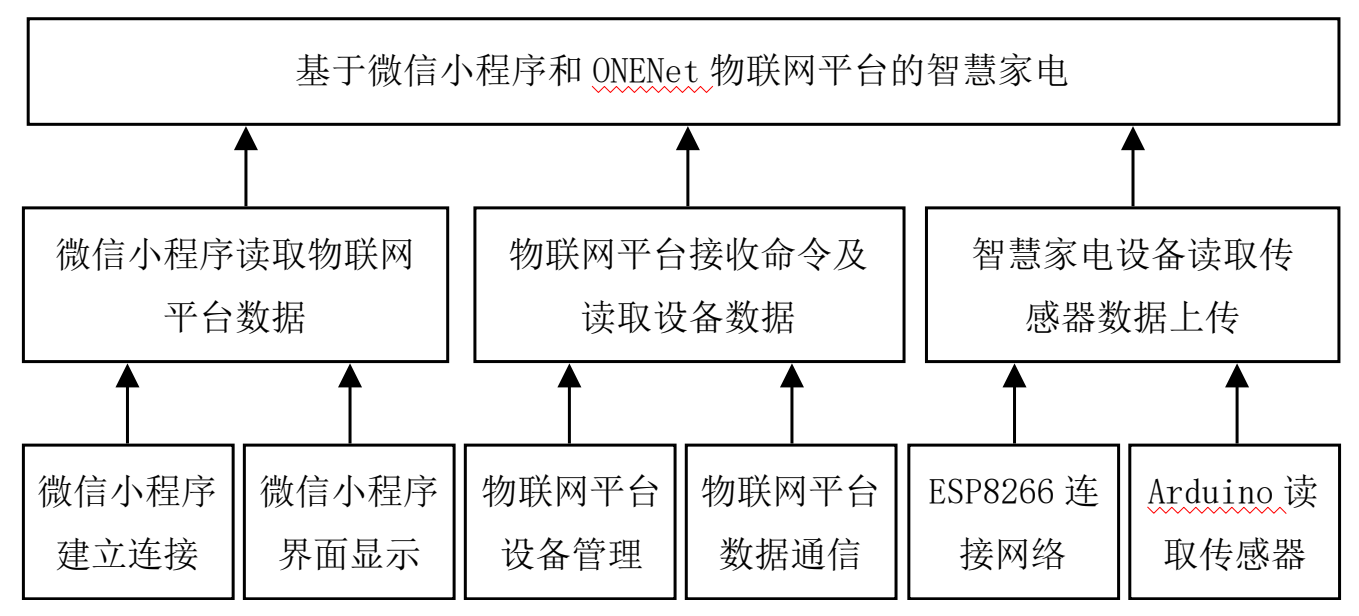

图 1 实践教学项目树形拆分图

\section{3 实施过程}

在实践教学过程中, 避免了学生单纯照学照做的情况, 注重引导学生积极探索和思考, 促使学生掌握分析的基本思 想和方法，使他们逐渐养成分析、探索之习惯，学会分析和 探索，并能得到有效结论 ${ }^{[4]}$ 。

\section{(1) 教学组织}

本项目为团队项目, 需要能够充分发挥团队成员的主 动性和积极性, 同时也需要加强团队间的沟通能力, 为了避 免出现团队成员自己组队，不利于培养每位同学综合能力 的情况, 在团队设计中, 选择了以宿舍为单位的团队组合 方式。

出发点主要在于 : 宿舍 4 人自行分工, 包括整体设计、 费用估算、具体实施和项目汇报 ; 能发挥各人专长, 增加沟 通交流，同时提升宿舍内的凝聚力；后面的宿舍在前面宿舍 项目的基础上开展，有助于宿舍间的沟通; 费用查询和估算,
有助于提高同学们的经济决策能力。

(2) 教学实施

集成产品开发 IPD 的流程主要采用结构化的开发流 程 ${ }^{[5]}$, 具体包括 : 任务书、概念、计划、开发、验证、发布 和生命周期。结合实践教学实际，通过校企双方教师研究， 由教师提供简单任务需求书，学生团队的项目开发流程专 注于概念、计划、开发和验证四个方面，具体流程如图 2 所示。

四个流程中每个流程对应相应的任务, 如计划流程, 需要完成的任务包括 : 项目定义及规格说明, 需要根据已 完善的需求文档对项目进行定义, 并对产品规格做出说 明; 元器件供应商选择, 需要在电商平台中查询元器件 供应商信誉、评价及元器件价格, 并选择相应的供应商; 产品预算需要根据选择的供应商, 进行初步的产品成本 估算。 


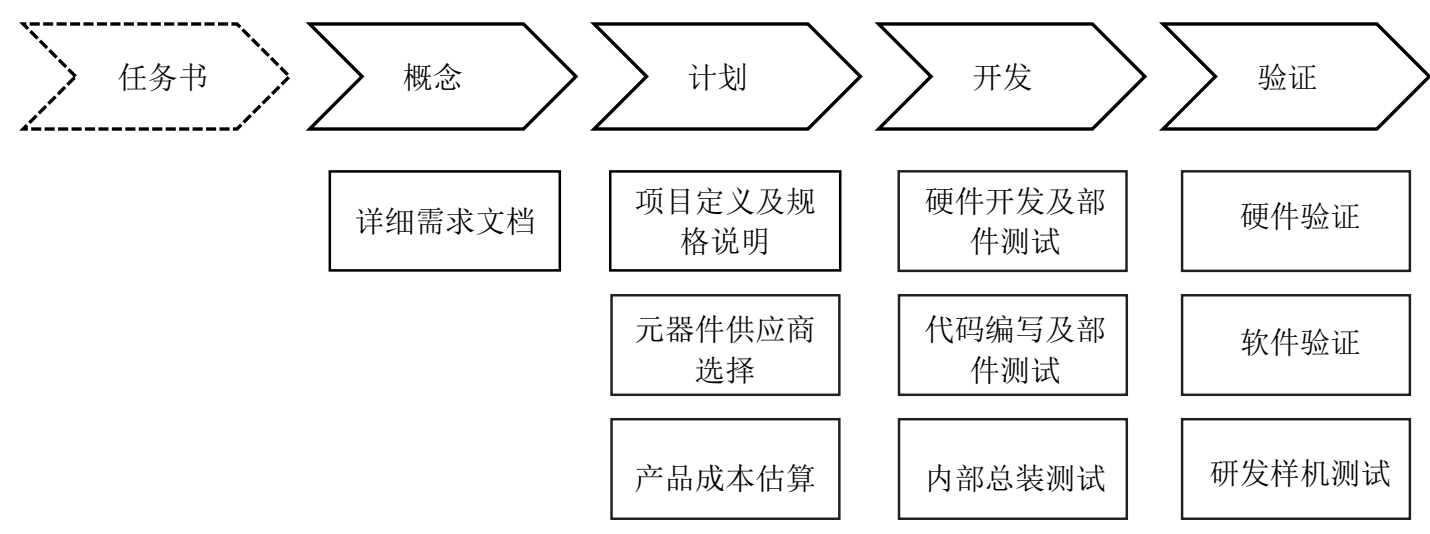

图 2 实践教学项目流程图

\section{(3) 教学评价}

采用集成产品开发开展实践教学, 目的是聚焦解决复 杂工程问题的能力, 因此在教学评价中没有使用闭卷考试的 形式，而是采用 PPT 汇报、设计报告和成果验收等形式对 团队成果进行评价, 包括教师评价和同学评价, 尽量能够客 观反应团队的工作量和个人能力提升。

\section{3 集成产品开发的实施效果}

通过集成产品开发在实践教学中的尝试，学生三方面 能力得到了提升 :

(1) 分析与解决问题能力, 通过思考分析问题原因所在, 通过查找期刊、开源代码、技术论坛以解决问题 ;

（2）协同开发项目管理能力，整体团队需要注重整体 设计、软硬件协调、进度把握项目管理方面的内容, 提高了 整体把握项目的能力和团队沟通能力 ;

（3）经济决策能力, 在元器件选择、供应商沟通及 成本估算方面得到了锻炼, 避免了实验室备好器材的拿来 主义, 进一步接近企业一线生产实际, 提高了经济决策 能力。

同时, 集成产品开发还可应用于团队比赛中，在 2020 年江苏省电子设计大赛中, 通过合理分工, 团队协作, 三名
同学组成的团队获得了本科组一等奖的优异成绩。

\section{4 结语}

在课程设计实践教学中应用集成产品开发, 聚焦于复 杂工程问题能力的培养，通过校企双方的案例设计及项目划 分, 增加了项目开发的广度和难度, 让学生真实体验到一线 工作的环境, 提高了学生的工作效率, 培养了学生综合设计 能力、协同开发项目管理能力和经济决策能力。接下来还需 要进一步丰富项目案例, 并结合教学过程数据分析教学效 果, 持续改进。

\section{参考文献}

[1] 杨毅刚, 唐浩, 宋庆, 等. 企业视角下新工科建设与工程教育 改革 [J]. 高等工程教育研究, 2018（03）:24-29+34.

[2] 臀波, 赵振军。“校企协同 +IPD” 深度融合的毕业设计模式研 究 [J]. 教育教学论坛, 2020（07）:33-34

[3] 王润云, 徐建波, 龚波. 基于 IPD 模式的本科毕业设计全过程 管理探索 [J]. 当代教育理论与实践, 2012,4（02）:52-53.

[4] 蒋宗礼. 本科工程教育: 聚焦学生解决复杂工程问题能力的培 养 [J]. 中国大学教学,2016 (11):27-30+84.

[5] 金佳波.基于集成产品开发（IPD）的 H 公司智能电表研发体 系优化研究 [D]. 浙江工业大学, 2019. 